\title{
Impact of Internet Information on Apple Growers' Adaptive Behaviors to Frost Disasters: Theory and Empirical Research from the Perspective of Psychological Perception
}

\author{
Haiyu Yang ${ }^{1,2}$, Wencong Cai ${ }^{1,2} \mathbb{D}$, Jundi Liu ${ }^{1,2}$ and Xuexi Huo ${ }^{1,2, *(\mathbb{D})}$ \\ 1 College of Economics and Management, Northwest A\&F University, Xianyang 712100, China; \\ yanghaiyu@nwafu.edu.cn (H.Y.); caiw@nwafu.edu.cn (W.C.); liujundi@nwafu.edu.cn (J.L.) \\ 2 Center of Western Rural Development, Northwest A\&F University, Xianyang 712100, China \\ * Correspondence: xuexihuo@nwafu.edu.cn
}

check for updates

Citation: Yang, H.; Cai, W.; Liu, J.; Huo, X. Impact of Internet Information on Apple Growers'

Adaptive Behaviors to Frost Disasters: Theory and Empirical Research from the Perspective of Psychological Perception. Agriculture 2021, 11, 905. https://doi.org/10.3390/

agriculture11100905

Academic Editor: Johannes Sauer

Received: 13 August 2021

Accepted: 20 September 2021

Published: 22 September 2021

Publisher's Note: MDPI stays neutral with regard to jurisdictional claims in published maps and institutional affiliations.

Copyright: (c) 2021 by the authors. Licensee MDPI, Basel, Switzerland. This article is an open access article distributed under the terms and conditions of the Creative Commons Attribution (CC BY) license (https:/ / creativecommons.org/licenses/by/ $4.0 /)$.

\begin{abstract}
As an effective tool for farmers to obtain agricultural information, the Internet has a profound impact on apple growers' perception of frost disasters and their adaptive behaviors. This paper constructed the theoretical analysis framework of "Apple growers' internet information acquisition-psychological perception-adaptive behavior to frost disaster", based on the data of 1020 apple growers in Shaanxi Province, empirically analyzing the impact of Internet information on apple growers' adaptive behaviors to frost disasters and its mechanism by the IV probit model and the intermediary effect model. The research found that the Internet information can significantly promote the apple growers' adaptive behaviors to frost disasters and has different effects on apple growers with different income levels and different management capabilities. Risk perception, effect perception, and risk attitudes have significant intermediary effects in the influence of the Internet information on apple growers' adaptive behaviors to frost disasters. Therefore, when governments take advantage of the Internet platform to help apple growers cope with frost disasters, they should fully consider the socio-economic conditions and psychological perception factors of apple growers and formulate targeted adaptation strategies.
\end{abstract}

Keywords: apple growers; adaptive behaviors; frost disasters; intermediary effect; internet information

\section{Introduction}

The apple industry is Shaanxi's agricultural pillar industry, and its healthy and stable development is of great significance to apple growers' income increase. However, Shaanxi's apple producing area has a continental monsoon climate, and the transition seasons of spring and autumn easily causes frost disasters due to the strength change of the winter monsoon and summer monsoon [1]. Generally, frost will occur at $-2{ }^{\circ} \mathrm{C}$ and below for more than $30 \mathrm{~min}$. The later the low temperature appears in the day, the more harmful the fruit trees will be. In recent years, the rapid rise in early spring temperatures, driven by warm winters, has led to an earlier-than-usual flowering of apple trees. In early and mid-April, the probability of frost will increase if the apple blossom period encounters abnormal weather such as the northwest cold current, cold air intrusion, or long-term rainy weather. This means that earlier flowering caused by climate change has increased the risk of frost damage to apple trees, which in turn has caused significant losses to apple farmers in Shaanxi [2]. For example, on 6-7 April 2018, the once-in-50-year severe cold current invaded northwestern China from north to south, causing the temperature in the apple producing areas of Shaanxi to drop to -8 to $-3{ }^{\circ} \mathrm{C}$. It is estimated that this frost will cause a loss of more than $40 \%$ of apple production in Shaanxi Province, that is, 4 million to 5 million tons [3].

Whether apple growers can take effective adaptive behaviors has become the key to coping with the risk of frost disasters. Studies have found that smoking and spraying 
antifreeze are the two main measures for apple growers to prevent frost disasters [2]. Specifically, smoking requires apple growers to obtain timely information about frost forecast from local meteorological departments. In the evening when the frost falls, the fruit growers alternately pile up the prepared sawdust, wheat bran, broken straw or weeds, fallen leaves in the orchard as fuel, and use fire to ignite the smoke. Practice also proved that spraying antifreeze can effectively reduce water transpiration of apple trees, thus reducing the impact of low temperature. From these general anti-frost measures, we can conclude that adaptive behavior refers to the decision-making process of apple growers adopting adaptive measures under uncertain conditions of frost disaster. The theory of rational behavior believes that the decision-making of individual behavior is not independent, but behavior judgment based on existing information [4]. However, apple growers are faced with the problem of lack of information resources and cannot obtain effective anti-frost technology information in time, resulting in a biased judgment of frost disasters risk, because apple producing areas are mainly distributed in hills, plateaus and even mountainous areas, the geographical location is remote and the communication infrastructure is relatively backward [5]. The lack of information has become the main obstacle for farmers to adopt adaptive measures [6].

The academia focuses on the impact of individual characteristics [7], production characteristics [2], and economic factors [8] of farmers on the adaptive behavior of meteorological disasters, while psychological factors are often ignored [9]. Hou Lingling et al. found that low-income farmers are more sensitive to drought events and believe that farmers facing severe drought impacts are more likely to adopt relevant adaptive measures [8]. Feng Xiaolong et al. found that the risk attitude has a significant positive impact on farmers' adoption of adaptive behaviors; and farmers' perception of the risk of meteorological disasters significantly affects their adoption of remedial behaviors [2]. Research by Mahmood showed that digital agricultural extension projects can significantly improve the accuracy of farmers' perception of climate risk and have a significant role in promoting the implementation of adaptation plans and behaviors [10]. Bryan et al. also believe that accurate and appropriate access to market information can enable farmers to adopt adaptive behavior to reduce climate risks [11]. It can be seen that effective information acquisition channels and psychological perception factors play an important role in the decision-making process of farmers' adaptive behaviors to meteorological disasters.

With the development of Internet technology and the popularization of mobile terminal equipment in rural areas, the Internet has become a main channel for farmers to obtain information [12]. By December 2020, the number of rural Internet users in China reached 309 million, accounting for $31.3 \%$ of the country's total Internet users [13]. However, there are different opinions in the academia whether the Internet has become the main channel for farmers to obtain information and whether the Internet information has a significant impact on farmers' decision-making behavior. Some scholars have concluded that farmers mainly obtain climate information and production information through face-to-face information exchange channels, such as participating in technical training [14] and joining cooperatives [15]. Some researchers believe that acceptance degree and effectiveness of farmers' access to agricultural information through different channels are different. Modern communication technologies (such as mobile phones, Internet access, etc.) have more effective impact on farmers' perception of climate change than traditional information acquisition methods (extension services, training sessions, and farmers' mutual aid groups) [16]. In addition, Wang Jianhua [17] believes that farmers can accumulate knowledge and skills through Internet technology, thus increasing their human capital. This shows that the Internet, as an information technology platform, has a significant impact on farmers in terms of equipment access and information capability acquisition. So, can the Internet improve apple growers' lack of information resources and then promote the anti-frost adaptive behavior? What is the mechanism of its effect? These issues need to be studied further. 
In summary, the existing literature has studied the influence factors of farmers' adaptive behaviors to meteorological disasters and the impact of Internet technology on farmers' information acquisition and adaptive behaviors of meteorological disasters, which lays a foundation for this study. However, the research on the influence mechanism of Internet information acquisition on farmers' adaptation behavior to meteorological disasters is still blank, especially the influence mechanism with farmers' psychological perception as the intermediary variable, which needs to be innovated in theory. Therefore, this paper takes apple growers in Shaanxi as the research object, and makes a systematic study on apple growers' adaptive behavior in response to frost disaster in an early spring blooming period (The reason for choosing frost as a meteorological disaster case: According to survey data, frost in 2020 is the disaster with the highest proportion of people affected among all disasters, reducing the income of $52.8 \%$ of the sample apple households by more than $30 \%$, and designs the theoretical analysis framework of Internet information affecting apple growers' anti-frost adaptive behavior through psychological perception path, and use the IV probit and intermediary effect model to test. The research results are helpful for apple growers to formulate effective measures to deal with frost disasters and provide practical reference.

\section{Theoretical Analysis and Research Hypothesis}

The occurrence of frost disaster is uncertain, including the time of occurrence, the scope, and the degree of the influence. Therefore, the decision-making of apple growers anti-frost adaptive behavior is a typical uncertain decision. Under the uncertain conditions of frost occurrence and impact, apple growers make anti-frost adaptive behavior decisions with the goal of maximizing expected net income and expected utility. Therefore, based on the analysis framework of Just et al. [18], the production function of apple growers in response to frost disaster can be expressed as follows:

$$
y=f(x)+g(x) \epsilon .
$$

In the above formulas, $y$ is the total apple yield of apple growers, $f(x)$ is the apple yield without frost disaster, $g(x)$ is the yield risk caused by frost disaster, that is, risk level; and $\varepsilon$ is the influence of frost disaster and obeys normal distribution. Therefore, the total apple yield obeys the normal distribution with mean $f(x)$ and variance $g^{2}(x)$. According to the theory of utility maximization of a rational economic man [19], facing the uncertainty of frost disasters, the decision-making goal of apple growers is to maximize their expected net income or expected utility. The expression is as follows:

$$
\operatorname{Max} H=E_{i^{*}}[U(R)]=E_{i^{*}}[U(p(f(m)+p g(z) \epsilon)-w(m+z)-r z)] \text { s.t. } m+z=x .
$$

In the Formula (2), $H$ is the net income, $E_{i}^{*}$ is the expected income of apple growers under the condition of the amount of information $i^{*}, \mathrm{U}$ is the income function, and $R$ is the factor affecting the net income. $p$ is the price of apple; $x$ is the total planting area, and $m$ and $z$ represent the areas where no anti-frost adaptive measures and anti-frost adaptive measures have been taken, respectively. $\mathrm{w}$ and $\mathrm{r}$ denote the cost of not taking adaptive measures and the additional cost of adopting adaptive measures. In order to achieve the optimization goal of Formula (2), apple growers choose whether to adopt adaptive measures in the face of the uncertainty of frost disaster. The first-order condition of Formula (2) is:

$$
\begin{gathered}
E_{i^{*}}\left[U^{\prime}(\cdot)\left(p f_{m}(\cdot)-w\right)\right]=0, \\
E_{i^{*}}\left[U^{\prime}(\cdot)\left(p g_{z}(\cdot) \epsilon-(w+r)\right)\right]=0 .
\end{gathered}
$$


Assume that the second-order condition of Equation (2) satisfies (That is, the convexity of the indifference curve, the marginal substitution rate of utility brought about by both the area with adaptive measures and the area without adaptive measures is diminishing). At the same time, let $m^{*}$ and $z^{*}$ respectively denote the interior solution of (2). Apple growers will take anti-frost adaptive measures only when the following conditions are met.

$$
g_{z}(z=0) \epsilon\left(i^{*}\right)>(w+r) \text {, where } g_{z}(z=0) \epsilon\left(i^{*}\right) \equiv E_{i^{*}}\left[g_{z}(0) \epsilon\right] .
$$

It can be seen from Equation (5) that the amount of information $i^{*}$ is the decisive factor affecting apple growers to adopt anti-frost adaptive measures. The information here specifically refers to agricultural information related to apple production, including local meteorological information and adaptive production technology information.

From the above analysis, the amount of effective information possessed by apple growers is the decisive factor affecting their adoption of anti-frost adaptive measures. As an effective information acquisition channel, the Internet can significantly reduce information search cost and increase the enthusiasm of apple growers to obtain agricultural information actively, thereby improving the quality of agricultural information acquisition. Moreover, different from the point-to-point information dissemination method of traditional media, the Internet can form an information-based screen market for all users [20], break down information barriers, and improve the amount and accuracy of agricultural information acquisition by apple growers. For example, apple growers can obtain information consulting services from the meteorological department and agricultural technology promotion department through mobile applications (APP) and obtain accurate frost disaster warning information and abundant adaptive technical information in time, so that they can make adequate response strategies to frost disasters. Therefore, this paper proposes research Hypothesis 1.

Hypothesis 1 (H1). Internet information acquisition promotes apple growers to adopt anti-frost adaptive behaviors.

The prerequisite for apple growers to adopt anti-frost adaptive behavior is to accurately perceive and identify the risk of frost disaster, and to judge the risk severity based on past disaster experience and relevant information. The information limitation causes apple growers to bias their perceptions of frost disaster risk and cannot make an accurate assessment of their own production status [21]. Coupled with the existence of fluke psychology and optimistic bias [9], apple growers will underestimate the risk severity of frost disaster, thereby reducing their willingness to take anti-frost adaptive measures. Only when the apple growers' risk perception of frost disaster exceeds a certain threshold, will they be motivated to adopt anti-frost adaptive behaviors. Secondly, apple growers can also obtain tips and judgments from surrounding villagers on disaster warning information through Internet social media, thereby enhancing their awareness of frost disaster risk. That is, Internet information acquisition can improve apple growers' risk perception level of frost disasters, and then promote their adoption of anti-frost adaptive behaviors. Therefore, this paper proposes research Hypothesis 2.

Hypothesis 2 (H2). Internet information acquisition has a positive impact on apple growers' anti-frost adaptive behaviors through the risk perception of frost disaster.

The perception of adaptive effects will directly affect farmers' motivation and intentions to adopt adaptive behaviors [22]. Due to the insufficient information on adaptive technologies, apple growers are unable to accurately recognize the average benefits brought by adaptive technologies. Moreover, the differences in farmers' technical knowledge will also lead to different effects of the same technology [21]. The use of Internet can improve the information asymmetry between apple growers and adaptive technology suppliers, and help apple growers obtain relevant information about frost disaster adaptation tech- 
nologies, so as to modify apple growers' expectations of technology benefits and promote technology adoption. For example, apple growers watching demonstration videos of anti-frost adaptive measures through the Internet can more intuitively recognize the implementation effect of adaptive measures, and then increase the possibility of adopting anti-frost adaptive behaviors. Therefore, this paper proposes research Hypothesis 3 .

Hypothesis 3 (H3). Internet information acquisition has a positive impact on apple growers' anti-frost adaptive behaviors through the perception of adaptive effects.

Apple growers make adaptive decision-making under the uncertain conditions of frost disaster, among which risk perception and risk attitude are important factors that influence apple growers to adopt anti-frost adaptive behaviors. The lack of access to information and insufficient information access capabilities have led to risk-aversion among most farmers [23]. Especially in remote apple production areas, due to the dual risks of natural disasters and market risks, apple growers are afraid to take anti-frost adaptive measures because of the damage to their interests. Through the diffusion of a large amount of information, the Internet can reduce technological uncertainty, and significantly alleviate farmers' risk aversion attitudes [24], thus alleviating the negative impact of risk-averse attitudes on technology adoption [25], which is beneficial to adopt anti-frost adaptive behaviors. Therefore, this paper proposes research Hypothesis 4.

Hypothesis 4 (H4). Internet information acquisition has a positive impact on apple growers' anti-frost adaptive behaviors by alleviating the risk aversion attitude of apple growers.

\section{Materials and Methods}

\subsection{Data Sources}

The data used in this paper are obtained from the field survey of China Apple Industry Research Group in Shaanxi province, the main producing area of apple, based on the stratified sampling method from November to December 2020. Firstly, the selection of the three sample counties classified the apple-growing regions according to the natural geographical conditions. Among them, Baota County in the hilly and gully region of Northern Shaanxi, Luochuan County in the Weibei Loess Plateau Region, and Fengxiang County in the Guanzhong Plain Region were selected as the sample counties. Secondly, three sample towns were selected in each sample counties by the typical sampling method based on the frost disaster degree, and three to four sample villages were selected in each sample towns. Finally, 30-40 apple households were randomly selected as the respondents in each village. The survey adopted face-to-face interviews and obtained a total of 1030 apple household samples. After excluding the samples with missing values, outliers and inconsistencies, a total of 1020 valid samples were obtained, with an effective rate of $99.0 \%$.

From the basic characteristics of the sample apple growers (Table 1), respondents are mainly male, with 783 males $(76.76 \%)$. There are fewer young apple growers under 40 , and more than half of farmers are over 55 . The education level of junior high school and below accounted for $85.69 \%$, and the overall education level was low. Nevertheless, most of them have rich experience in apple planting, $88.24 \%$ of which have been planted for more than 10 years. The distribution of per capita income is relatively even, which is basically in line with the statistical data of 13,316 yuan per capita disposable income of rural residents in Shaanxi Province (National Bureau of Statistics of China). The apple planting area is mostly concentrated in 5-15 mu, mainly operated by small households. 
Table 1. Sample statistical characteristics.

\begin{tabular}{|c|c|c|c|}
\hline Variable & Classification & Frequency & Percent \\
\hline Gender & Male $=1$ & 783 & 76.76 \\
\hline$($ Male $=1 ;$ Female $=0)$ & Female $=0$ & 237 & 23.24 \\
\hline \multirow{4}{*}{ Age (years) } & $25-40$ & 81 & 7.94 \\
\hline & $40-55$ & 409 & 40.10 \\
\hline & $55-70$ & 558 & 54.71 \\
\hline & 70 and above & 53 & 5.20 \\
\hline \multirow{4}{*}{ Schooling year (years) } & Illiteracy (0) & 84 & 8.24 \\
\hline & Elementary education (0-7) & 306 & 30.00 \\
\hline & Junior high school (7-10) & 484 & 47.45 \\
\hline & High school and above (10-23) & 146 & 14.31 \\
\hline \multirow{4}{*}{ Apple planting year (years) } & Less than 10 & 120 & 11.76 \\
\hline & $10-20$ & 225 & 22.06 \\
\hline & $20-30$ & 380 & 37.25 \\
\hline & 30 and above & 295 & 28.92 \\
\hline \multirow{4}{*}{ Per capita income (yuan) } & Less than 10,000 & 217 & 21.27 \\
\hline & $10,000-20,000$ & 320 & 31.37 \\
\hline & $20,000-30,000$ & 201 & 19.71 \\
\hline & 30,000 and above & 282 & 27.64 \\
\hline \multirow{3}{*}{ Apple planting area (mu) } & Less than 5 & 271 & 26.57 \\
\hline & $5-15$ & 517 & 50.69 \\
\hline & 15 and above & 232 & 22.75 \\
\hline
\end{tabular}

\subsection{Measures}

\subsubsection{Dependent Variable}

Spraying antifreeze and smoking can change the microclimate in the orchard, increase the local environmental temperature of the orchard, thereby reducing the harm of low temperature to apple trees and increasing the flowering rate and fruit setting rate [26]. When apple growers use either spraying antifreeze or smoking to deal with frost disasters, it is defined as apple growers adopting anti-frost adaptive behavior, which is assigned a value of 1 ; and neither spraying antifreeze nor smoking is assigned a value of 0 .

\subsubsection{Independent Variable}

In the interviews, it was found that apple growers use the Internet for various purposes, including obtaining news, agricultural information, instant messaging, and entertainment videos. In order to distinguish apple growers' Internet usage purposes, the independent variable is defined as whether apple growers obtain agricultural information through mobile phones or computers $(\mathrm{Yes}=1, \mathrm{No}=0$ ). The agricultural information here specifically refers to local weather information and adaptive production technology information related to frost. Moreover, in order to compare the influence of the Internet and traditional agricultural information acquisition channels on adaptive behaviors, this paper also adds traditional media and face-to-face communication as a reference to the Internet channels for comparative analysis. The traditional media variable is defined as whether apple growers obtain agricultural information through television or radio (Yes $=1$, $\mathrm{No}=0$ ). The face-to-face communication variable is defined as whether apple growers obtain agricultural information through face-to-face communication with relatives or friends $($ Yes $=1, \mathrm{No}=0)$. 


\subsubsection{Intermediary Variable}

The mediating effect analysis in this paper is divided into three paths: The first is risk perception. Risk perception is the subjective judgment of apple growers on the risk severity of frost disaster. The answer to apple growers' question "How do you think the impact of frost disaster on apple production in the last 10 years has been? (Very light $=1$, relatively light $=2$, general $=3$, more serious $=4$, very serious $=5$ )" is used as an indicator to measure the risk perception. Considering the problem of risk identification bias caused by farmers' bounded rationality, we compare the subjective risk perceptions of farmers based on the frequency of frost disasters in the past 10 years. If there is a big difference, we will re-inquire the farmers' subjective perceptions and correct them. The second is effect perception. We ask the apple growers separately "What is the effect of spraying antifreeze to cope with frost disasters like; what is the effect of smoking to cope with frost disasters like? (No effect $=1$, basically no effect $=2$, general $=3$, relatively good effect $=4$, very good effect $=5)^{\prime \prime}$, and the sum of the two answers ranging from 2 to 10 is used as a comprehensive indicator to measure the effect perception. The higher the score, the better the effect perception. The third is risk attitude. According to previous research, the risk attitude of farmers and technology adoption behavior are significantly correlated $[22,25,27,28]$. Therefore, this paper uses the answer to the question "If the village promotes new agricultural technology, when did you adopt them compared with other people in the village? (Latest $=1$, relatively late $=2$, middle $=3$, relatively early $=4$, earliest $=5)^{\prime \prime}$ as an indicator to measure the subjective risk attitude of apple growers. From 1 to 5 , the degree of risk preference increases in order.

\subsubsection{Control Variable}

Referring to the previous literature $[7,29,30]$, the control variables designed in this paper are individual characteristics, family characteristics, production characteristics, and regional dummy variables.

Individual characteristic variables include gender, age, schooling year and apple planting year, reflecting the human capital endowment characteristics of apple growers.

Family characteristics variables include number of family labor, apple income, and distance from county. We also take the logarithm of income from apples. Growing apples is a labor-intensive and capital-intensive industry. The number of family labor and income of apple growers have a significant impact on their production decisions. The farther away from the county, the more blocked the information is. The distance from the county reflects the information level of apple growers.

Production characteristic variables include apple planting area and soil quality of apple orchards. The apple planting area reflects the specialization degree and labor intensity. Large-scale growers pay more attention to disaster prevention measures, but the labor cost is also more. Therefore, the overall direction of the effect on adaptive behavior is uncertain. The soil quality of apple orchards is divided into five grades (very barren $=1$, relatively barren $=2$, general $=3$, relatively fertile $=4$, very fertile $=5$ ), reflecting the agricultural production conditions.

The regional dummy variables control the development concentration degree of the apple industry and county geographic location by introducing the county dummy variable, among which Fengxiang County is the control group. Table 2 shows descriptive statistics for all variables. 
Table 2. Descriptive statistic.

\begin{tabular}{|c|c|c|}
\hline Variable & Mean & Std.Dev \\
\hline \multicolumn{3}{|c|}{ Dependent variable } \\
\hline Anti-frost adaptive behavior $(\mathrm{Yes}=1 ; \mathrm{No}=0)$ & 0.854 & 0.353 \\
\hline \multicolumn{3}{|c|}{ Independent variables } \\
\hline Internet information (Yes $=1 ; \mathrm{No}=0)$ & 0.568 & 0.496 \\
\hline Traditional media $(Y e s=1 ; \mathrm{No}=0)$ & 0.841 & 0.366 \\
\hline Face-to-face communication $($ Yes $=1 ;$ No $=0$ ) & 0.804 & 0.397 \\
\hline \multicolumn{3}{|c|}{ Individual characteristic variables } \\
\hline Gender $($ Male $=1 ;$ Female $=0)$ & 0.768 & 0.423 \\
\hline Age & 54.514 & 9.627 \\
\hline Schooling year & 7.302 & 3.444 \\
\hline Apple planting year & 21.709 & 9.195 \\
\hline \multicolumn{3}{|c|}{ Family characteristic variable } \\
\hline Number of family labor & 2.646 & 1.020 \\
\hline Apple income $(\ln )$ & 10.079 & 2.276 \\
\hline Distance from county $(\mathrm{km})$ & 43.188 & 50.893 \\
\hline \multicolumn{3}{|c|}{ Production characteristics variables } \\
\hline Apple planting area $(\mathrm{mu})$ & 10.229 & 8.331 \\
\hline Soil quality of apple orchards & 3.538 & 1.018 \\
\hline \multicolumn{3}{|c|}{ Regional dummy variable } \\
\hline Luochuan $($ Yes $=1 ; \mathrm{No}=0)$ & 0.315 & 0.465 \\
\hline Baota $($ Yes $=1 ;$ No $=0)$ & 0.325 & 0.468 \\
\hline \multicolumn{3}{|c|}{ Intermediary variable } \\
\hline Risk perception & 4.308 & 1.008 \\
\hline Effect perception & 6.567 & 1.684 \\
\hline Risk attitude & 3.445 & 1.205 \\
\hline
\end{tabular}

\subsubsection{Grouped Descriptive Statistics}

Table 2 shows that $56.8 \%$ of apple growers obtain agricultural information through the Internet, which is far lower than the $83.0 \%$ of the sample apple growers who use the Internet, and $43.2 \%$ of the sample apple growers cannot effectively use the Internet to obtain agricultural information. In order to illustrate the influence of Internet information acquisition on the anti-frost adaptive behavior and psychological perception of apple growers, this paper uses the Internet to obtain agricultural information to group sample apple growers (see Table 3). The proportion of apple growers who use the Internet to obtain agricultural information adopts anti-frost adaptive behavior is $88.9 \%$, which is $8.2 \%$ higher than apple growers who do not use the Internet to obtain agricultural information. In terms of psychological perception, apple growers who use the Internet to obtain agricultural information have higher risk perception, effect perception, and risk attitudes than those who do not use the Internet to obtain agricultural information. It shows that Internet information acquisition is related to frost resistance adaptive behavior and farmers psychological perception. However, whether the correlation is inevitable still needs to be empirically tested. The grouping descriptive statistical characteristics of other control variables are also listed in Table 3. 
Table 3. Grouping descriptive statistics.

\begin{tabular}{cccc}
\hline Variable & $\begin{array}{c}\text { Internet Access to } \\
\text { Information Group } \\
\text { Mean (1) }\end{array}$ & $\begin{array}{c}\text { No Internet Access to } \\
\text { Information Group } \\
\text { Mean (2) }\end{array}$ & $\begin{array}{c}\text { Diff } \\
\text { (1)-2) }\end{array}$ \\
\hline Anti-frost adaptive behavior & 0.889 & 0.807 & $0.082^{* * *}$ \\
Risk perception & 4.406 & 4.179 & $0.227^{* * *}$ \\
Effect perception & 6.661 & 6.442 & $0.219^{* * *}$ \\
Risk attitude & 3.594 & 3.249 & $0.345^{* * *}$ \\
Gender & 0.796 & 0.730 & $0.066^{* *}$ \\
Age & 52.282 & 57.444 & $-5.163^{* * *}$ \\
Schooling year & 8.166 & 6.168 & $1.998^{* * *}$ \\
Apple planting year & 22.143 & 21.141 & $1.003^{*}$ \\
Number of family labor & 2.615 & 2.687 & -0.072 \\
Apple income (ln) & 10.197 & 9.924 & $0.272^{*}$ \\
Distance from county (km) & 42.478 & 44.119 & -1.641 \\
Apple planting area (mu) & 10.628 & 9.706 & $0.922^{*}$ \\
Soil quality of apple orchards & 3.636 & 3.410 & $0.225^{* * *}$ \\
Luochuan & 0.342 & 0.279 & $0.063^{* *}$ \\
Baota & 0.299 & 0.358 & $-0.059^{* *}$ \\
\hline
\end{tabular}

Note: Diff is the difference between the two groups' means. ${ }^{*}, * *$ and ${ }^{* * *}$ respectively represent significance levels of $10 \%, 5 \%$, and $1 \%$ of the $t$-test.

\subsection{Model Specification}

3.3.1. The Influence of Internet Information Acquisition on the Anti-Frost Adaptive Behavior

Since the dependent variable is a binary dummy variable, the binary Logistic model is chosen for analysis. This is also the benchmark model for this paper.

$$
\ln \left[\frac{P}{1-P}\right]=b_{0}+\sum_{i=1}^{i} b_{i} X_{i}+\varepsilon,
$$

where $P$ is the probability of apple growers adopting anti-frost adaptive behavior; $(1-P)$ is the probability of apple growers not adopting anti-freezing adaptive behavior; $b_{0}$ is the regression intercept; $X_{i}$ represents Internet information, individual characteristics, family characteristics and other control variable respectively. $b_{i}$ is the estimated coefficient of $X_{i}$; and $\varepsilon$ is the error term.

\subsubsection{Probit Model}

There may be endogenous problems in the impact of Internet use on farmers' adaptive behavior. First is the self-selection problem. The use of the Internet to obtain agricultural information may be affected by their personal characteristics, such as education level, family income, and business management capabilities. The second problem is the causal relationship. For example, the apple growers' demand for anti-frost adaptive behaviors will enable them to obtain agricultural information through the Internet. The third problem is the missing variable. There are some unobservable factors that affect the status of the two, such as managerial ability and farmers motivation.

In view of the above reasons, this paper introduces an instrumental variable and uses IV probit model to overcome the endogenous problem. We selected "the proportion of farmers' relatives and friends who use the Internet" as the instrumental variable for farmers' Internet information acquisition. In rural acquaintance communities, the socioeconomic status of the farmers and their close relatives and friends are similar, and they will have imitative behaviors and learning effects. The higher the proportion of relatives and friends of a farmer who use the Internet, the greater the probability that the farmer will use the Internet to obtain information. Therefore, the instrumental variable meet the relevance requirements. On the other hand, the proportion of relatives and friends using the Internet will not directly affect farmers' anti-frost adaptive behaviors and meet exogenous requirements. To further empirically test the rationality of the instrumental variable, the 
endogenous test results show that the exogenous assumption of the explanatory variable is rejected at a significance level of $10 \%$. Therefore, it is necessary to use instrumental variables to correct the endogenous problem. The F value is 20.03 , which is greater than 10 , so there is no weak instrumental variable problem.

\subsubsection{Mediating Effect Test}

According to the previous analysis, the agricultural information obtained by apple growers relying on the Internet will influence the anti-frost adaptive behavior through psychological perception factors. The mediating effect test method proposed by Wen Zhonglin and Ye Baojuan [31] is used to test the mediating effects of risk perception, effect perception, and risk attitude.

$$
\begin{gathered}
Y=c X+e_{1}, \\
M=a X+e_{2}, \\
Y=c^{\prime} X+b M+e_{3}
\end{gathered}
$$

In the above formulas, $X$ is the independent variable Internet information, $M$ stands is the intermediary variable, including risk perception, effect perception and risk attitude, $Y$ is the anti-frost adaptive behavior, and $e_{1}, e_{2}$, and $e_{3}$ are residuals.

\section{Results}

\subsection{The Effect of Internet Information on Anti-Frost Adaptive Behavior}

In order to identify the effective influence of the agricultural information from different channels on apple growers' anti-frost adaptive behaviors, we added the Internet information, traditional media and face-to-face communication variable in Models 1, 2, and 3, respectively. As shown in Table 4, only Internet information has a significant effect on anti-frost adaptive behavior, the other two are not significant, and the influence coefficient of the Internet variable is greater than the other two. This proved that compared with face-to-face communication and traditional media, the use of Internet information

\begin{tabular}{|c|c|c|c|}
\hline \multirow{2}{*}{ Variable } & \multicolumn{3}{|c|}{ Anti-Frost Adaptive Behavior } \\
\hline & Model 1 & Model 2 & Model 3 \\
\hline Internet information & $\begin{array}{l}0.520 * * \\
(0.203)\end{array}$ & & \\
\hline Traditional media & & $\begin{array}{c}0.172 \\
(0.244)\end{array}$ & \\
\hline Face-to-face communication & & & $\begin{array}{c}0.012 \\
(0.239)\end{array}$ \\
\hline Control variable & controlled & controlled & controlled \\
\hline Number of Obs & 1020 & 1020 & 1020 \\
\hline
\end{tabular}
effectively promoted apple growers' anti-frost adaptive behaviors.

Table 4. The effect of different information acquisition channels on anti-frost adaptive behaviors.

Although the regression results in Table 4 show that Internet information can significantly and positively affect the anti-frost adaptive behavior of apple growers, it does not consider the endogenization of Internet information acquisition. Therefore, the introduction of instrumental variables is necessary. In view of this, our analysis is mainly based on the regression results of the IV Probit model (Table 5).

As shown in the first stage of IV Probit, the proportion of Internet use positively affects Internet information acquisition at a significant level of $1 \%$, so it can be considered that there is no problem of weak instrumental variables. Traditional media and faceto-face communication variables have a significant positive impact on apple growers' Internet information acquisition. It shows that information-conscious farmers will obtain 
agricultural information through different media. The use of different media are positively related and not mutually exclusive.

Table 5. The effect of the Internet information on anti-frost adaptive behavior of apple growers.

\begin{tabular}{|c|c|c|}
\hline \multirow{2}{*}{ Variable } & \multicolumn{2}{|c|}{ IV Probit } \\
\hline & First Stage & Second Stage \\
\hline Internet information & & $1.506^{* *}(0.752)$ \\
\hline Proportion of Internet use & $0.005^{* * *}(0.001)$ & \\
\hline Traditional media & $0.127^{* * *}(0.039)$ & $-0.115(0.178)$ \\
\hline Face-to-face communication & $0.183^{* * *}(0.036)$ & $-0.293(0.201)$ \\
\hline Gender & $0.070 *(0.036)$ & $-0.140(0.142)$ \\
\hline Age & $-0.013^{* * *}(0.002)$ & $0.012(0.013)$ \\
\hline Schooling year & $0.028^{* * *}(0.004)$ & $-0.038(0.028)$ \\
\hline Apple planting year & $0.007^{* * *}(0.002)$ & $0.007(0.009)$ \\
\hline Number of family labor & $-0.016(0.014)$ & $0.067(0.055)$ \\
\hline Apple income (ln) & $-0.001(0.007)$ & $0.051 * *(0.024)$ \\
\hline Distance from county & $-0.000(0.000)$ & $-0.002 * *(0.001)$ \\
\hline Apple planting area (mu) & $0.003(0.002)$ & $0.017 *(0.010)$ \\
\hline Soil quality of apple orchards & $0.021(0.014)$ & $-0.044(0.056)$ \\
\hline Luochuan & $-0.123^{* * *}(0.040)$ & $0.584^{* * *}(0.187)$ \\
\hline Baota & $-0.064(0.050)$ & $0.107(0.198)$ \\
\hline _cons & $0.136(0.184)$ & $-0.588(0.756)$ \\
\hline Number of Obs & 1020 & 1020 \\
\hline
\end{tabular}

In addition, gender, age, schooling year, and apple planting year all significantly affect apple growers' Internet information acquisition behavior. Specifically, men are more willing to use the Internet to obtain agricultural information than women, possibly because men are the main agricultural laborers and decision makers at home, and they need the Internet to expand their information acquisition channels to provide them with effective decision-making information. The older the apple growers, the lower their ability to learn new technologies, which will inhibit their Internet information acquisition behavior. The higher the schooling year of the apple growers, the stronger their information acquisition and processing capabilities, and the more willing they are to use the Internet to obtain agricultural information. The longer the apple growers' planting years, the higher their emphasis on agriculture, and then the apple grower has a stronger demand for information acquisition, which in turn will promote the behavior of using Internet to obtain information.

As shown in the second stage of IV Probit, Internet information acquisition has a significant positive impact on the anti-frost adaptive behavior of apple growers, while the impact of traditional media and face-to-face communication variables are not significant. This shows that compared to traditional media and face-to-face communication information acquisition channels, Internet information can have a higher influence on the decisionmaking of apple growers' anti-frost adaptive behaviors. This may be because the Internet is more convenient and quicker in obtaining information, and the information quality is relatively high. Thus, $\mathrm{H} 1$ is verified. 


\subsection{Heterogeneity Analysis}

\subsubsection{Internet Information, Income Level, and Anti-Frost Adaptive Behavior}

Farmers with different income levels will have different perceptions of extreme weather events and their choice of adaptive measures [8]. In order to investigate whether there is a significant intergroup difference in the impact of Internet information on the anti-frost adaptive behaviors of apple growers with different income levels, this paper divides the survey samples into three groups based on the three quartiles of the total income of the survey sample households, named low-income group, middle-income group, and high-income group, respectively, and perform the group regression test. The regression results show (Table 6) that the low-income group and middle-income group apple growers' Internet information positively affects the anti-frost adaptive behavior at a $5 \%$ significance level, while the estimated coefficient of the high-income group is not significant. This may be because the high-income group of apple growers has relatively rich material capital and available information resources, and thus has strong resistance to frost disaster risks. Therefore, they do not need to rely too much on the Internet to obtain agricultural information to deal with frost disasters. However, middle-income and low-income farmers need to use Internet information channels to reduce their information asymmetry and improve their adaptability to frost disasters.

Table 6. The heterogeneity of income level and management ability.

\begin{tabular}{cccccc}
\hline Variable & Low-Income & $\begin{array}{c}\text { Middle- } \\
\text { Income }\end{array}$ & $\begin{array}{c}\text { High- } \\
\text { Income }\end{array}$ & & \multicolumn{2}{c}{$\begin{array}{c}\text { Technology Demonstration } \\
\text { Households }\end{array}$} \\
\cline { 5 - 6 } & & & Yes & Yes \\
\hline $\begin{array}{c}\text { Internet } \\
\text { information }\end{array}$ & $0.885^{* *}$ & $0.834^{* *}$ & 0.115 & $1.443 *$ & $0.441^{* *}$ \\
$(0.398)$ & $(0.349)$ & $(0.415)$ & $(0.875)$ & $(0.215)$ \\
\hline Control variable & controlled & controlled & controlled & controlled & controlled \\
\hline Number of obs & 342 & 338 & 340 & 122 & 898 \\
\hline $\begin{array}{l}\text { Note: ** and * respectively represent significance levels of 5\%, and } 10 \% \text { (double tails). The values in brackets are } \\
\text { robust standard errors. }\end{array}$ & & & &
\end{tabular}

\subsubsection{Internet Information, Management Ability, and Anti-Frost Adaptive Behavior}

According to the previous analysis, the Internet information acquisition of apple growers is a self-selective behavior, which is affected by their individual characteristics. We group the survey samples by "whether apple growers are technology demonstration households" to verify the difference in the impact of Internet information acquisition on apple growers with different management capabilities. Technology demonstration households refer to farmers with a certain level of education and rich planting experience. They can actively apply, demonstrate and promote new agricultural varieties, new technologies, new products, and new models, and they have a good demonstration and leading role. Technology demonstration households have strong technological awareness and have a strong interest in new technologies, new achievements, and various new things. Therefore, a reasonable expectation is: Internet information has a more significant impact on the anti-frost adaptive behavior of technology demonstration households. As shown in Table 5, Internet information acquisition positively affects the anti-frost adaptive behavior of technology demonstration households and non-technology demonstration households at significance levels of $10 \%$ and $5 \%$, and has a greater impact on technology demonstration households. This indicates that technology demonstration households can better use the Internet to obtain the inherent value of agricultural information and apply it to the practice of anti-frost adaptive behaviors. Therefore, policy executors should play the leading role of demonstration households in the process of using the Internet to promote agricultural information. 


\subsection{Mediating Effect Analysis}

Behavioral economics believes that human decision-making behavior will be affected by psychological factors [32]. The mediating effect of psychological factors are shown in Table 7, where the standardized Internet information variable has a positive impact on anti-frost adaptive behavior, risk perception, effect perception, and risk attitude with at least at a significance level of $5 \%$. Risk perception, effect perception, and risk attitude have significant positive effects on anti-frost adaptive behaviors. After introducing risk perception, effect perception, and risk attitudes in turn, the influence of Internet information on anti-frost adaptive behavior is still significant, but the impact coefficient has declined. The results show that risk perception, effect perception, and risk attitude pass the mediating test and are part of mediating effects. Thus, Hypotheses $2-4$ are verified.

Table 7. The mediating effect of risk perception, effect perception and risk attitude.

\begin{tabular}{|c|c|c|c|c|}
\hline Variable & $\begin{array}{l}\text { Anti-Frost } \\
\text { Adaptive } \\
\text { Behavior }\end{array}$ & $\begin{array}{c}\text { Risk } \\
\text { Perception } \\
\text { (Std) }\end{array}$ & $\begin{array}{c}\text { Effect } \\
\text { Perception } \\
\text { (Std) }\end{array}$ & $\begin{array}{c}\text { Risk } \\
\text { Attitude } \\
\text { (Std) }\end{array}$ \\
\hline \multirow[t]{2}{*}{ Internet information (Std) } & $\begin{array}{l}0.259 * * \\
(0.101)\end{array}$ & $\begin{array}{l}0.079 * * \\
(0.032)\end{array}$ & $\begin{array}{c}0.096^{* * *} \\
(0.033)\end{array}$ & $\begin{array}{l}0.072 * * \\
(0.033)\end{array}$ \\
\hline & \multicolumn{4}{|c|}{ Anti-frost adaptive behavior } \\
\hline Internet information (Std) & $\begin{array}{l}0.232 \text { ** } \\
(0.103)\end{array}$ & $\begin{array}{l}0.216^{* *} \\
(0.102)\end{array}$ & & \\
\hline Risk perception (Std) & $\begin{array}{c}0.304^{* * *} \\
(0.087)\end{array}$ & & & \\
\hline Effect perception (Std) & & $\begin{array}{c}0.455^{* * *} \\
(0.095)\end{array}$ & & \\
\hline Risk attitude (Std) & & & & \\
\hline
\end{tabular}

Note: Std represents the standardized variable (the same below). ${ }^{* *}$ and ${ }^{* *}$ respectively represent significance levels of $1 \%$ and $5 \%$ (double tails). The values in brackets are robust standard errors.

The Internet has increased the possibility for apple growers to obtain meteorological information services and has increased their awareness and risk perception of frost disasters, thereby increasing the degree of risk perception. Previous related studies have shown that risk perception has a positive effect on farmers' behavior decision-making [33,34]. In order to reduce the risk of production decline caused by frost, apple growers are willing to adopt anti-frost adaptive behaviors. The Internet has also enabled apple growers to obtain agricultural information from multiple channels, breaking the information barrier between apple growers and agricultural technology suppliers, enabling apple growers to fully understand the effects of frost disaster adaptation measures, and alleviating apple growers' doubts about adopting adaptive measures. Finally, Internet access to information effectively alleviates the risk-averse attitude of apple growers by reducing the uncertainty in the production adaptation decision-making process. All of the above are conducive to the adoption of adaptive behaviors by apple growers.

It should be noted that the variables selected in this paper are all categorical variables, and only the method proposed by Wen Zhonglin and Ye Baojuan [31] may not be enough to explain the empirical test results, so we use the distribution of the product method of Fang Jie [35] and Tofighi [36] to test the robustness of the mediating effect. Using the RMediation package of $R$ software to calculate the $90 \%$ confidence interval of $Z_{a} \times Z_{b}$, the confidence intervals corresponding to the three intermediary variables are $(0.006,0.046),(0.017,0.075)$, and $(0.002,0.035)$, all excluding 0 . Therefore, the mediating effect of the three intermediary variables has been further verified. 


\subsection{Robustness Test}

\subsubsection{Robustness Test of Benchmark Regression}

Considering that there is a self-selection problem in whether apple growers obtain agricultural information through the Internet, the propensity score matching method (PSM) is used to conduct a robustness test. In order to ensure the effectiveness of matching, this paper tests the balance of the three matching methods to check whether there is a systematic difference between the treated group and the control group after the matching. The results are shown in Table 8. After matching, the value of Pseudo $\mathrm{R}^{2}$ is very small, almost zero, the likelihood ratio test is rejected at the $1 \%$ significance level before the match, but after the match, it is not rejected, and the bias mean and median are both greatly reduced. B value is all less than $25 \%$. It can be seen that after propensity score matching, the obvious deviation of observable variables between the treatment group and the control group is basically eliminated, and the balance test is passed. Based on the above analysis, the PSM result is reliable. The result show that (Table 9), whether using nearest neighbor matching, radius matching or kernel matching, Internet information significantly affects anti-frost adaptive behavior, which proves that the benchmark regression result is relatvely stable.

Table 8. Explanatory variable balance test results before and after matching.

\begin{tabular}{cccccc}
\hline Matching Method & Pseudo $\mathbf{R}^{\mathbf{2}}$ & LR Chi $^{\mathbf{2}}$ & $\begin{array}{c}\text { MeanBias } \\
\mathbf{( \% )}\end{array}$ & $\begin{array}{c}\text { MedBias } \\
\mathbf{( \% )}\end{array}$ & $\begin{array}{c}\text { B } \\
\mathbf{( \% )}\end{array}$ \\
\hline Unmatched & 0.162 & 226.02 & 22.50 & 13.60 & 99.70 \\
Neighbor match & 0.007 & 10.15 & 4.10 & 3.50 & 19.00 \\
Radius match & 0.007 & 10.16 & 4.50 & 3.70 & 19.10 \\
Kernel match & 0.006 & 10.05 & 4.50 & 3.80 & 19.00 \\
\hline
\end{tabular}

Table 9. Estimated results of PSM.

\begin{tabular}{ccccc}
\hline Matching Method & Matched Meanbias & Difference & Standard Error & T Test Value \\
\hline Neighbor match & 4.1 & 0.100 & 0.033 & $3.10^{* * *}$ \\
Radius match & 4.5 & 0.067 & 0.030 & $2.26^{* *}$ \\
Kernel match & 4.5 & 0.068 & 0.030 & $2.29^{* *}$ \\
\hline
\end{tabular}

Note: ${ }^{* * *}$ and ${ }^{* *}$ respectively represent significance levels of $1 \%$ and $5 \%$ (double tails).

\subsubsection{Robustness Test of Mediating Effect}

This paper performed the robustness test of mediating effect by selecting different agents to measure the independent variable for regression. Agriculture APP allows apple growers to conveniently obtain agricultural information using their smart phones. Representative agricultural APPs include "Huinong.com", "Agricultural Stewardship", "Agricultural Technology Exchange", and so on. Specifically speaking, this paper uses the answer to the question "Do you have an agricultural APP installed on your phone (Yes = 1, $\mathrm{No}=0$ )" to construct a variable to replace the Internet information. The test results are shown in Table 10. The replaced variable Agriculture APP can still affect the anti-frost adaptive behavior through the three psychological variables. So far, the mediating effect has been verified again. 
Table 10. The mediating effect of agricultural APP on anti-frost adaptive behavior.

\begin{tabular}{|c|c|c|c|c|}
\hline & $\begin{array}{l}\text { Anti-Frost } \\
\text { Adaptive } \\
\text { Behavior }\end{array}$ & $\begin{array}{c}\text { Risk } \\
\text { Perception } \\
\text { (Std) }\end{array}$ & $\begin{array}{c}\text { Effect } \\
\text { Perception } \\
\text { (Std) }\end{array}$ & $\begin{array}{c}\text { Risk } \\
\text { Attitude } \\
\text { (Std) }\end{array}$ \\
\hline \multirow[t]{2}{*}{ Agricultural APP (Std) } & $\begin{array}{c}0.386^{* * *} \\
(0.120)\end{array}$ & $\begin{array}{l}0.058 * * \\
(0.028)\end{array}$ & $\begin{array}{c}0.101^{* * *} \\
(0.031)\end{array}$ & $\begin{array}{c}0.156^{* * *} \\
(0.031)\end{array}$ \\
\hline & \multicolumn{4}{|c|}{ Anti-frost adaptive behavior } \\
\hline Agricultural APP (Std) & $\begin{array}{c}0.364^{* * *} \\
(0.120)\end{array}$ & $\begin{array}{c}0.337^{* * * *} \\
(0.104)\end{array}$ & $\begin{array}{r}0.3 \\
(0 .\end{array}$ & \\
\hline Risk perception (Std) & $\begin{array}{c}0.304^{* * *} \\
(0.086)\end{array}$ & & & \\
\hline Effect perception (Std) & & $\begin{array}{c}0.444^{* * *} \\
(0.098)\end{array}$ & & \\
\hline Risk attitude (Std) & & & \multicolumn{2}{|c|}{$\begin{array}{l}0.197 * \\
(0.096)\end{array}$} \\
\hline
\end{tabular}

\section{Conclusions}

From a psychological perspective, this paper designs an analysis framework for the influence of Internet information on the anti-frost adaptive behavior of apple growers, emphasizing that the heterogeneity of family income, management ability, and the psychological factors of apple growers should be considered when studying adaptive behaviors. The following conclusions can be drawn: First, Internet information can significantly promote the adoption of anti-frost adaptive behavior by apple growers. Second, Internet information has a heterogeneous effect on apple growers with different income levels and different management capabilities. It has a significant positive impact on the adoption of anti-frost adaptive behavior by middle-income and low-income apple growers, but has no significant impact on high-income apple growers. Internet information significantly and positively affects the anti-frost adaptive behavior of technology demonstration households and non-technology demonstration households, and has a greater impact on technology demonstration households. Third, the mediating effect research results show that risk perception, effect perception, and risk attitude play a part of the mediating role in the influence of Internet information on the anti-frost adaptive behavior of apple growers.

The conclusions of the research have enriched the results of interdisciplinary fields such as agricultural economics, psychology and behavioral economics, and the policy implications of this paper are as follows: (1) Improve the communication infrastructure in remote rural areas, expand the Internet access rate, encourage farmers to obtain agricultural information through the Internet, and bridge the "digital gap" in information acquisition by low-income and middle-income farmers. (2) Meteorological departments should take the advantages of Internet technology to promptly push meteorological disaster warning information to increase the alertness of apple growers to frost disaster risk. (3) The agricultural technology extension department should give full play to the demonstration role of technology demonstration households, and promote targeted anti-frost adaptive technologies to farmers through a combination of online promotion and offline demonstration, to help apple growers effectively master adaptive response technologies, so as to eliminate their worries about adaptive technology effect. (4) Promote meteorological disaster prevention knowledge using Internet platforms and give psychological counseling to affected apple growers to alleviate the aversion caused by the uncertain risk of frost.

Of course, this study has certain limitations. The subjective psychological characteristics of farmers are complex and obscure, and it is difficult to accurately measure it with the 5-point Likert scale. Although we have used calibration methods, there may still be some measurement bias problems. In future work, relative objective indicators should be used to measure psychological characteristics as much as possible. This is the direction that should be improved in future research. 
Author Contributions: Conceptualization, H.Y.; methodology, H.Y.; software, H.Y.; validation, X.H., formal analysis, W.C.; investigation, H.Y.; resources, X.H.; data curation, H.Y.; writing-original draft preparation, H.Y.; writing-review and editing, W.C., J.L. and X.H.; visualization, H.Y.; supervision, X.H.; project administration, X.H.; funding acquisition, X.H. All authors have read and agreed to the published version of the manuscript.

Funding: This research was funded by The Earmarked Fund for China Agriculture Research System (No. CARS-28) and the "APC" was funded by the National Modern Apple industry Technology System of the China Agriculture Research System, Center of Western.

Institutional Review Board Statement: Not applicable.

Informed Consent Statement: Informed consent was obtained from all subjects involved in the study.

Data Availability Statement: The data presented in this study are available on request from the corresponding author. The data are not publicly available due to data management.

Acknowledgments: The author would like to thank the administrative staff of the agricultural sector in research area for field research help, Liqi Chu, for their valuable suggestions in the revision of the paper, and Feilong Weng, for his valuable suggestions in the method of the paper, which inspired me a lot. I would like to express my sincere thanks.

Conflicts of Interest: The authors declare no conflict of interest.

\section{References}

1. Song, H.L.; Wan, H.L.; Zhu, C.C. Research on frost disaster events and effects in Shaanxi region for the past 1400 years. J. Arid Land Resour. Environ. 2018, 32, 170-176.

2. Feng, X.L.; Chen, Z.X.; Huo, X.X. Influencing factors of apple farmer adaptation to meteorological disasters. Resour. Sci. 2015, 37, 2491-2500.

3. Wang, J.Y. Damage of late frost and post-disaster recovery measures in fruit producing areas of Northwest Loess Plateau. China Fruits 2018, 192, 1-3. [CrossRef]

4. Fishbein, M.; Ajzen, I.; Belief, A. Belief, attitude, intention, and behavior: An introduction to theory and research. Contemp. Sociol. $1977,10,6$

5. Yan, B.B.; Zhang, Q.Q.; Liu, T.J. Can mobile phone promote the adoption of IPM technology by farmers? J. Agrotech. Econ. 2020, $45-59$.

6. Deressa, T.T.; Hassan, R.M.; Ringler, C.; Alemu, T.; Yesuf, M. Determinants of farmers' choice of adaptation methods to climate change in the Nile Basin of Ethiopia. Glob. Environ. Chang. 2009, 19, 248-255. [CrossRef]

7. Zhang, Z.Y.; Wang, J.X.; Huang, J.K. Adaptation to freezing disaster in agricultural production: Research on adoption status and determinants. J. Agrotech. Econ. 2014, 233, 4-13.

8. Hou, L.L.; Wang, J.X.; Huang, J.K. The perception and adaptive measures of extreme drought events for farmers with different income levels: Empirical analysis on large scale survey of farmers in 9 provinces of China. J. Agrotech. Econ. 2016, $259,24-33$.

9. Grothmann, T.; Patt, A. Adaptive capacity and human cognition: The process of individual adaptation to climate change. Glob. Environ. Chang. 2005, 15, 199-213. [CrossRef]

10. Mahmood, N.; Arshad, M.; Mehmood, Y.; Shahzad, M.F.; Kächele, H. Farmers' perceptions and role of institutional arrangements in climate change adaptation: Insights from rainfed Pakistan. Clim. Risk Manag. 2021, 32, 100288. [CrossRef]

11. Bryan, E.; Ringler, C.; Okoba, B.; Roncoli, C.; Silvestri, S.; Herrero, M. Adapting agriculture to climate change in Kenya: Household strategies and determinants. J. Environ. Manag. 2013, 114, 26-35. [CrossRef] [PubMed]

12. Liu, Z.H.; Xin, X.; Lv, Z.W. Does farmers' access to agricultural information on the internet promote the land transfer. J. Agrotech. Econ. 2021, 310, 100-111.

13. CNCCI. The 47th China Statistical Report on Internet Development; China Internet Network Information Center: Beijing, China, 2021.

14. Feng, X.L.; Liu, M.Y.; Huo, X.X. An empirical study on the behavior of specialized farmers' adaptation to climate change under water resource constraint: A case study of 663 apple growers in Shaanxi Province. J. Agrotech. Econ. 2016, $257,18-27$.

15. Tong, Q.M.; Zhang, L.; Zhang, J.B. An analysis of oriented characteristics and influential factors of farmers' adaptation to climate change in 10 representative counties and cities of Hubei Province. J. China Agric. Univ. 2019, 24, 194-205.

16. Hasibuan, A.M.; Gregg, D.; Stringer, R. Accounting for diverse risk attitudes in measures of risk perceptions: A case study of climate change risk for small-scale citrus farmers in Indonesia. Land Use Policy 2020, 95, 104252. [CrossRef]

17. Wang, J.H.; Li, L.T. Research on the impaction of information means on developing human capital and rural economy: Empirical analysis of fixed phone and computer internet data. East China Econ. Manag. 2013, 27, 119-122+126.

18. Just, R.E.; Pope, R.D. Production Function Estimation and Related Risk Considerations. Am. J. Agric. Econ. 1979, 61, $276-284$. [CrossRef]

19. Saha, A.; Love, H.A.; Schwart, R. Adoption of Emerging Technologies Under Output Uncertainty. Am. J. Agric. Econ. 1994, 76, 836-846. 
20. Zhang, Y.L. Internet, Information-elements and Screening-market: A theoretical model of modern network economy and its application. Econ. Res. J. 2016, 51, 147-161.

21. Qiao, D.; Lu, Q.; Xu, T. Social networks, information acquisition and water-saving irrigation technology adoption: An empirical analysis from Minqin County, Gansu Province. J. Nanjing Agric. Univ. 2017, 17, 147-155+160.

22. Le Dang, H.; Li, E.; Nuberg, I.; Bruwer, J. Farmers' assessments of private adaptive measures to climate change and influential factors: A study in the Mekong Delta, Vietnam. Nat. Hazards 2014, 71, 385-401. [CrossRef]

23. Ghadim, A.; Pannell, D.J.; Burton, M.P. Risk, uncertainty, and learning in adoption of a crop innovation. Agric. Econ. 2005, 33, 1-9. [CrossRef]

24. Zhang, S.H.; Gu, H.Y. How can the application of the internet and information technologies alleviate rural residents' risk aversion attitude? Analysis based on the micro data of China Family Panel Studies. Chin. Rural Econ. 2020, 430, 33-51.

25. Gao, Y.; Niu, Z.H. Risk aversion, information acquisition ability and farmers' adoption behavior of green control techniques. Chin. Rural Econ. 2019, 8, 109-127.

26. Zhang, D.Y. Analysis and Evaluations of Integrated Prevent Techniques on Apple Spring Frost-Freezing; Shandong Agricultural University: Taian, China, 2015.

27. Liu, E.M. Time to Change What to Sow: Risk Preferences and Technology Adoption Decisions of Cotton Farmers in China. Rev. Econ. Stat. 2013, 95, 1386-1403. [CrossRef]

28. Gao, Y.; Zhang, X.; Lu, J.; Wu, L.; Yin, S. Adoption behavior of green control techniques by family farms in China: Evidence from 676 family farms in Huang-huai-hai Plain. Crop Prot. 2017, 99, 76-84. [CrossRef]

29. Lv, Y.R.; Chen, S.F. An analysis of farmers' cognition of climate change and their adaptive behaviors. Chin. Rural Econ. 2010, 7, 75-86.

30. Mustapha, B.; Salau, E.S.; Galadima, O.E.; Ali, I. Knowledge, Perception and Adaptation Strategies to Climate Change Among Farmers of Central State Nigeria. Sustain. Agric. Res. 2013, 2, 107-117.

31. Wen, Z.L.; Ye, B.J. Analyses of mediating effects: The development of methods and models. Adv. Psychol. Sci. 2014, 22, 731-745. [CrossRef]

32. Yu, W.Z.; Luo, X.F.; Li, R.R.; Xue, L.F.; Huang, L. The paradox between farmer willingness and their adoption of green technology from the perspective of green cognition. Resour. Sci. 2017, 39, 1573-1583.

33. Qi, Q.; Zhou, J.; Wang, X.L. Study on the relationship between farmer risk perception and pesticide application behavior response: An empirical test from vegetable farmers of Liaoning Province. J. Agrotech. Econ. 2020, 2, 72-82.

34. Deng, Z.; Dai, L.; Deng, L.; Peng, P. Research on farmer's cognition and behavior response in rural living environment improvement: Taking Dongting Lake wetland reserve as an example. J. Agrotech. Econ. 2013, 2, 72-79.

35. Fang, J.; Wen, Z.L.; Zhang, M.Q. Mediation analysis of categorical variables. J. Psychol. Sci. 2017, 40, 471-477.

36. Tofighi, D.; Mackinnon, D.P. RMediation: An R package for mediation analysis confidence intervals. Behav. Res. Methods 2011, 43, 692-700. [CrossRef] [PubMed] 